University of Massachusetts Amherst

From the SelectedWorks of Laura A. Valdiviezo

Fall 2019

\title{
"To Educate for Them in Different Ways;" Defining Inclusion in Popular and Intercultural Education in Argentina and Peru
}

Laura A. Valdiviezo

Jennifer Lee O'Donnell 


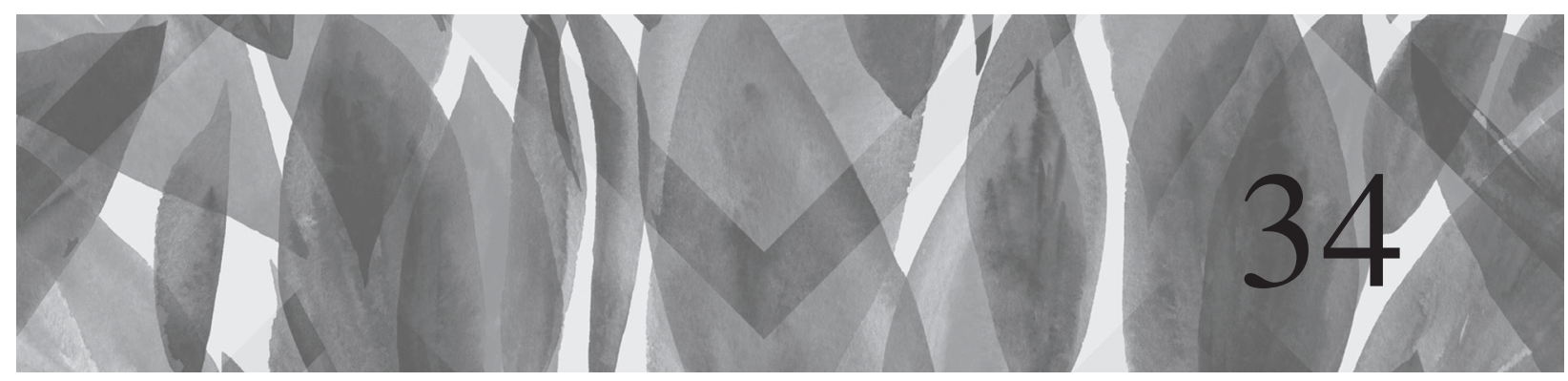

\title{
'To Educate for Them in Different Ways': Defining Inclusion in Popular and Intercultural Education in Argentina and Peru
}

\author{
Laura A. Valdiviezo and Jennifer Lee O'Donnell
}

\section{INTRODUCTION}

The last decade of the twentieth century witnessed the emergence of multiculturalism as a central concept in various education and social policy government initiatives across Latin America. As part of a global phenomenon based on United-Nations-driven initiatives, including Education for All (UNESCO, $1990,2000)$ and various declarations on the rights of Indigenous people to education (UN Declaration on the Rights of Indigenous Peoples, 2008), words like inclusion and diversity began to populate official policy discourse and change - at least on paper and institutional and public attention turned to marginalized populations. Thus, in societies marked by grave social, economic, and political disparities like Argentina and Peru, policy calls for greater inclusion have been made as a solution to problems concerning public and institutional spheres. However, grave inequalities impacting these countries' most vulnerable populations persist and are far from being solved. In this chapter we aim to examine what inclusion means in the context of both countries and how it continues to be challenged and redefined by different societal actors. We present two cases of inclusive education in order to argue that understanding what actors do in the field is needed to design and implement initiatives and policy aimed at addressing inequality. Such knowledge can aid in the conception of non-top-down alternatives for inclusion in a more realistic and effective manner.

Governments in Latin American countries like Argentina and Peru have turned fresh attention to the public sector and particularly to public education - an area that has remained under-resourced and neglected among other government sectors. They have also welcomed human and material resources aimed at addressing problems concerning inclusion in public schools and educational attainment in general. In most cases, the main argument for attention to education fits a neoliberal agenda that points to the urgency 
of preparing a competitive workforce for the 21st-century global market. International agencies, as well as local and non-governmental organizations, have sponsored a number of education initiatives oriented to serve populations from low socioeconomic groups (e.g. The German Technical Mission and CARE, among others). In the case of Peru and Argentina, government-sponsored education programs aim for the inclusion of diverse populations, with particular attempts being made to socialize underserved communities into mainstream society.

Under discourses of inclusion and diversity, the challenges of tending to historically excluded, stigmatized, and invisibilized populations - from Indigenous people to poor and working-class urban laborers - are creating new tensions. Prevailing institutional discourses that emphasize cultural and linguistic homogenization aimed at national unity compete with emerging discourses of diversity that purport to honor difference in the life of contemporary societies. Moreover, comparisons between policy and practice in these contexts have revealed the co-existence of discourses from government and education actors in the field, where, in many cases, government officials and educators have shown contradictory conceptualizations of inclusion in education spaces.

The analysis of policy discourse and program implementation in Intercultural Bilingual Education (IBE), in Peru, for example, has revealed that government officials maintain top-down exclusionary views of IBE policy. In her ethnographic study of educators' beliefs and practices in IBE Indigenous programs, Valdiviezo (2009; Valdiviezo \& Valdiviezo-Arista, 2008) has examined how government views continue to resemble ideas of the schoolhouse as a space for mainstreaming diverse children; these views have often denied Indigenous cultural and linguistic practices inside the classroom (Valdiviezo, 2009). By contrast, teachers in Valdiviezo's study welcomed Indigenous practices in their daily lessons. Analysis has revealed the contradictions of education practice, where sometimes innovative teaching that included diverse linguistic and cultural practices co-existed with practices that emphasized rote memorization and dictation in the dominant language.

In Argentina, education policy designates that the inclusion of diverse populations in schools is a right for all citizens, and that learning institutions are obliged to recognize the particularities of different social groups' educational needs (UNESCO, 2007). In her ethnographic study of popular educators in Buenos Aires, however, O'Donnell (in press) found public teachers suspicious of these policies in light of the neoliberalization of the country's public institutions in recent years. As in Valdiviezo's research, contradictions emerged in the cracks between inclusive education as mandated by government policy and teachers' beliefs regarding how representation should present itself inside their classrooms. In spite of this policy initiative, the innovative teaching methods, inclusive of diverse linguistic and cultural students, did not sit comfortably with the government's overall plan of a more marketized, one-size-fits-all brand of schooling. The educators presented here were forced to instead find alternative means of practicing inclusion while still working under public school directives. Inspired by the work of Brazilian educator and activist Paulo Freire, these educators adopted the popular education model to push back against policies detrimental to inclusion and achievement in public schools. The analysis presented demonstrates how teachers have formed coalitions of educators, students, and community members to discuss, debate, and build upon their ideas and knowledge to enable a more inclusive education community to emerge for all citizens.

The present chapter analyzes cases from a range of sometimes contradictory understandings of inclusion and diversity of educators in the field. From concepts to practice, the authors aim to broaden the definition and complexity of education that embraces diversity and 
inclusion in Argentinean and Peruvian multicultural programs. Through ethnographic inquiry, the authors depict both the epistemologies in these education programs as well as the dilemmas educators and participants face in their daily practices. Beyond detailed descriptions, the present chapter emphasizes how such contradictions and dilemmas can become transformative if used to broaden theoretical analysis and policy design on diversity and inclusion in education.

\section{POPULAR EDUCATION AND ITS ROLE IN ARGENTINA}

Revolution swept Latin America in the 1960s and 1970s, led by socialist groups, various trade unionists, journalists, artists, university students and professors. Popular education was emerging throughout Latin America during this time with a push for inclusive, multicultural education that began with the Cuban revolution and its drive for universal literacy and community development. It continued on to Brazil with the pedagogy of Paulo Freire, who sought to 'redefine the relationship between education and human beings, society and culture' (Jara, 2010, p. 291).

Throughout his writing, lectures and workshops, Freire (1985) insisted that educators teach people how to interpret and understand systems of oppression in the hope that they may be able to make changes to situations they see unjust (Darder \& Mirón, 2006). Training local members of the education community to become leaders, for example, is crucial in Freirean pedagogy to guarantee that marginalized people 'gain the skills and power to take their problems into their own hands' (Fink \& Arnove, 1991, p. 226). Popular education's curriculum is designed with conscientização or critical consciousness in mind, so that a deeper understanding of the social structures of society can supervene. Teaching that fosters conscientização develops through analysis and dialogue focused on social, political, and economic injustices, and it is here where teachers and students develop the skills necessary for them to take political action and make social change (Macedo, 2006).

Following the teachings of Freire, popular education in Argentina also began in the 1960s. However, the movement was forced to go underground throughout the 1970 s as the country suffered under an oppressive military dictatorship (1976-1981) that unleashed state sponsored terrorism on 30,000 Argentinean leftists. Groups struck the hardest included teachers, professors, students, journalists, activists, artists, and their supporters (Lewis, 2002). As a result of the government's excessive debts acquired during this time, Argentina's path to democratization in the years following the fall of the military regime included new economic policies piloted by the World Bank and International Monetary Fund (IMF) that offered the troubled country financial backing by way of a classic, marketbased model designed to transform the active role of the welfare state. With devastating consequences to poor and working-class communities, conservative president Carlos Menem (1989-1999), thrust Argentina into the global economy through free-market economic policies, regional alliances, and state disengagement from industry and services in favor of privatization and deregulatory trade systems. The years that followed were times of economic and political turmoil, marked by de-industrialization, the privatization of national industries, mass unemployment, frozen bank accounts, a valueless peso, and the obliteration of welfare programs for poor and working-class communities (Ball, Fischman, \& Gvirtz, 2003).

Though the country has since taken a radical turn left under two populist presidents (both Kirchner administrations in 2003-2007 and 2007-2015), many today fear that the new governance of neoliberal president Mauricio Macri (2016-) will keep public education entrenched in laissez-faire policies that continue to neglect the needs of poor 
and working-class citizens. This section of our chapter explores how teachers on the left have been using popular education pedagogy to push back against policies of the right, particularly those detrimental to inclusion and educational attainment in public schools for all citizens.

\section{Inclusion and Access in Argentine Schools}

In this section we discuss work with one social movement, El Frente Popular Darío Fernández (FPDF), which carried out educational and recreational projects to meet the needs of young people residing in poor communities by providing them with space for learning, selfmanagement, and solidarity (further work on FPDF's pedagogy can be found in O'Donnell \& Sadlier, 2017; O'Donnell, in press). O'Donnell, the researcher, attended a series of six popular education workshops with the group that ran monthly from May to October of 2013. FPDF held these workshops specifically for public school and pre-service teachers because they felt, on the whole, that the popular education paradigm was absent in traditional teacher training programs in Buenos Aires. The workshops were organized to provide support tools so that educators could bring the popular education methods of Paulo Freire to their classrooms.

Through commentary that arose during small-group discussions and interviews, these educators provided insights into what inclusion means in Argentinean classrooms today. We highlight perspectives on inclusivity from pre-service teachers Camila, Ana, Florencia, Paula, and Galinda, and, finally, from Hortencia - a workshop facilitator who has been a public educator in Buenos Aires for over ten years - and who shows how educators incorporated more inclusive, popular education methods in their teaching during a school-wide strike at Public School 31.

These educators spoke of a recent rightwing education policy that focused primarily on student test scores and delivered top-down mandates through an inflexible curriculum that did not fulfill the needs of their learning communities. They spoke of the city's turn to privatized education, which made overcrowding a treacherous reality in many public schools. They also spoke of the consequences teachers who wanted to remain in the public sector but were forced to teach multiple course loads at various schools across Buenos Aires, creating distance between each other, and between themselves and their students, and the communities that housed their schools.

These conditions inspired teachers to seek a connection with one another professionally and politically at the popular education workshops to discuss issues pertinent to education. Through discourse that emerged in interviews, small group discussions and presentations, educators revealed the barriers that made it impossible for some to participate in building the public education community they envisioned.

More than anything teaching should take a political stance. I can't have the thought in my head that I teach just so my students can one day earn a salary in a company. [Galinda, Small Group Discussion, June 8, 2013]

Yes! We need to teach them how to break the company instead. [Camila, Small Group Discussion, June 8, 2013 my italics]

For many, the idea of breaking with the established rules, and the establishment, was a fundamental part of their beliefs about their roles as teachers, as they felt there was little room for creativity, freedom, and holistic approaches to educating students inside the formal school system. One way teachers were able to acquire more freedom was in finding ways to play along with the bureaucracy, appeasing them, while still breaking the rules to follow their own curriculum.

In traditional schools you have to play along with what the administrators are asking for, like giving numerical grading at the end of each semester. But like, Fernando participates a lot in class, he does not like writing, he likes talking best, and then I 
give a grade? How do I evaluate someone like this? So when the school asks me for a grade, I create my own grading rules. [Paula, Small Group Discussion, June 8, 2013, my italics]

One of the collective beliefs agreed upon by educators in the workshop was that the formal education system teaches educators and students only how to respect the rules or norms, but they felt it was their job to strategize new ways to challenge and eventually transform these norms for a more inclusive learning environment. One cultural rule participants in the workshop wanted to break with was the construction of Argentina's national identity, which has historically privileged European whiteness while dismissing Indigenous, African, or other racial groups living throughout the country. Educators were aware of these disparities and felt that though Argentina's public education system represents groups with a mix of people from different societies and cultures, meeting the different needs of those groups in the classroom was underdeveloped in their schools and pre-service teacher training.

We ignore issues important to Bolivians who live here - questions like how many get to go to college - or we ignore the Mapuche traditions, or various other issues minority groups face in Argentina. We don't always like different realities, or realities we aren't used to, but it is important to understand them in order to educate for them in different ways. [Florencia, Small Group Discussion, May 11, 2013]

Many realized that racism was present in Argentina, and that it was particularly grounded in the country's identification with European whiteness that stigmatized the diverse social realities that make up the population. As such, educators sought to subvert the myth of the white Argentinean. Hortencia, a teacher at School 31 in the neighborhood of Luedo, a state-run public middle school with morning and afternoon classes, led discussions and activities in order to teach how fun and games could be used to successfully stage protests against the often non-inclusive classroom ethos of public education initiatives, and thus addressing how she and her co-workers were able to thwart some of the negative practices and systemic problems of whiteness, exclusion, alienation, and exploitation prominent within their community.

\section{REDEFINING INCLUSION THROUGH THE POPULAR EDUCATION PARADIGM}

School 31 hosted approximately 900 children from the district in numerous grade levels, with roughly 30 students per class. The building where Hortencia taught was located in a complex of government-subsidized high rises in the neighborhood of Villa Luedo, in the city of Buenos Aires. Her students were children of working-class, precarious workers. Their parents were construction workers, repaired refrigerators, were employees of small businesses, maids, dressmakers, drove buses or taxis, and some were unemployed. Many were children of migrants from within the interior of Argentina, or they were from Bolivia, Paraguay, and other neighboring countries.

Hortencia shared with workshop participants how she and her fellow teachers were able to incorporate popular pedagogy that was inclusive of the cultures represented inside their classrooms, while at the same time confronting the isolating neoliberal policy existing in public schools. She began by discussing some of the devastating policies implemented since President Macri's political party came into power. She explained that in 2008 Macri's government advanced neoliberal policies against public schools that had a devastating impact throughout the city. Faced with the first onslaught of the educational policy plans of Macrismo, unions called for isolated and sporadic strikes. While public school teachers protested, however, the union could not protect their salaries unless the schools were filled with students. An agreedupon stance of adhering to the strikes and 
demonstrations, while trying not to empty schools, was negotiated. Teachers needed to be in their classes, making clear that the work stoppage did not mean the abandonment of schools. Instead they held a Strike Day.

Hortencia and her fellow teachers believed popular education was not only relevant to classroom activities with students, but offered an ethos inclined toward a more inclusive education community that ran counter to the privatized, test-score-driven Macrismo policy that muted the diverse bodies present in Buenos Aires schools. As she put it during an interview:

There is one important thing to remember and that is - popular education can transform the rules. It can transform time and space. It can transform the ways we connect with one another. It is constantly making the rules, breaking the rules, and changing the rules. I can't think of a better way of talking about politics than that. [Hortencia, Interview, August 17, 2013]

Hortencia explained to the workshop participants that during the Strike Day teachers, families, and students convened at the school to play, listen, dance, debate, create, and learn in defense of public schools, effectively utilizing the tenants of popular public pedagogy. Kids organized games for other kids, teachers organized workshops, and community members came to participate or to put on cultural performances. There were live performances from a folk choir; Arab dancers; flute, bass, and guitar bands; Andean dancers; and parades. As Hortencia described it, games were used in a strategic way to foster community solidarity during the Strike Day.

I think that's what school is, something made jointly by teachers, kids, and families. School 31 is getting better and this is not a coincidence. It is the result of effort and participation, and the shared work of children, teachers, and families. It's a real and hopeful victory for the whole community. [Hortencia, Large Group, August 17, 2013]

Hortencia noted that it was important for parents and teachers to think of solutions to the issues the community faced together. As she put it, there is no other way to build inclusive spaces if peer learning and community building is not present. From these notions, the popular education paradigm was used to construct long-term projects like building proposals, strengthening emotional ties, changing attitudes and ways of relating to one another, and fostering the desire and the pleasure of doing work with others.

Storytelling, for example, was an important part of the Strike Day, as represented in an activity proposed by educators and students for the flag-raising ceremony. It became a significant practice in bringing about a plurality of voices often in traditional public schooling. A ritual with military roots reserved for honoring the national flag and the country's anthem became re-appropriated to allow space for stories and legends told predominantly by Indigenous community members.

\footnotetext{
We wanted to consider diversity, multiculturalism, the American identity, and so we came up with the idea of telling American tales and legends. On the first day of the Strike Day, various community members were asked in advance to narrate a story during the raising of the flag. We decided to ask those who came to then draw a picture of whatever they wanted about what they had heard. [Hortencia, Large Group, August 17, 2013]
}

Rather than saluting the flag, community members came out to listen to stories that included 'The Legend of the Bat', 'The Legend of the Turtle', 'Hanaq Pacha or The Wedding in Heaven', 'The Divorce of the Lion and Lioness', and 'The Tamanduá Inventor'. Drawings, paintings, and sculptures were born from these stories and came to fertilize images used to render a collective mural painted within the school's courtyard. From this activity, the school commissioned community members and professional artists living in Villa Luedo to paint a mural based on the stories and creative drawings. Hortencia explained, 'It wasn't just a few of us painting. It wasn't just artists. Everyone painted!' [Hortencia, Large Group, August 17, 2013].

During the Strike Day, popular education practices that included games and play were 
incorporated into the day's activities so that the community members could come together not through revolution, anger, or confrontation with the government, but through fun, rule-breaking, and the body in contact with other bodies. Teachers who participated in the workshops agreed that solidarity was one of the only ways of combatting the alienating, exploitive repercussions of neoliberal education policy, and, as such, a key component of the workshops was building this solidarity amongst participants.

Learning to build solidarity in the communities where they teach, through the popular education framework, was transformative for the teachers involved in these workshops. It enabled them to vocalize the systemic problems their communities faced within the education system, while bringing forth action plans that held the potential to foster culturally diverse representation and inclusion within the school community. Through dialogue and practices that encouraged breaking with the established rules of pedagogy to create new ones, educators were able to envision change in the traditional public schooling they were contesting.

\section{Classroom Teachers Breaking the Rules}

Popular education pedagogy promotes the importance of coalition building through social movement practices that are often able to form stronger ties in education communities. Through the FPDF workshops, public school teachers had the opportunity to come together to discuss, debate, and build upon their ideas and knowledge for a more inclusive classroom, with the belief that they needed to break the established rules of pedagogy to create new ones.

In demonstrating the importance of community, solidarity, and relationship building for those who have been impacted by neoliberalism's alienating and exploitive tactics which were targeting the public education system throughout Argentina, these insights provide an initial roadmap to developing the types of relationships educators felt they needed to transform traditional schooling throughout the country.

The popular education workshops of FPDF promoted a more complex education than was found in traditional public schools, embracing diversity and inclusion. Teachers expressed awareness of their efforts in relation to the educational, social, and political climate in Argentina. In this climate, they faced material as well as ideological challenges but were also able to imagine and promote education practices that were inclusive, community oriented, and confrontational toward the taken-for-granted rules and regulations of classrooms governed by neoliberal policy makers.

\section{INCLUSION IN INTERCULTURAL BILINGUAL EDUCATION: THE CASE OF PERU}

The challenges of inclusive education in Peru, as in Argentina, derive from the existing discourses and practices that promote homogenization as the goal and solution to social and economic problems in the country (Valdiviezo, 2009, 2014). Rooted in centuries of classist, discriminatory and racist institutional and social practices inherited from colonialism, policy initiatives responded typically to two main dogmatic criteria. On the one hand, if only marginalized populations had access to the same infrastructure and quality education as elite groups, problems would be solved; and on the other hand, if only marginalized populations enacted values and cultural practices in the way that elite families did, their problems would be solved. Many underlying assumptions to this type of common ideological reasoning has permeated the ways in which institutions - and in this case, schools - have designed and undertaken potential solutions. In most cases the 
perspectives for solutions assume deficiency in the potential beneficiaries: in this view, the poor and marginalized lack not only material resources but also cultural ones. This assumed deficiency blames the victim while exonerating elite groups from any connection with and responsibility towards the rest of society. As Mariategui (1972), among other social critics, has long argued, the structures of hierarchy and power that sustain these elites are built on a colonial history that suppressed and enslaved Indigenous people and helped colonizers and their descendants to concentrate and maintain political and economic power in contemporary Peru.

Before discourses of inclusion and diversity became part of national discourse, educating Indigenous populations was not a priority. If education was offered, the emphasis was on denying the Indigenous language and culture through punishment and oppressive classroom environments, where Indigenous children learned that their language, their culture, and their communities were worthless. While schools taught Indigenous students that they were backwards and deficient, racism in society taught them that even as they learned their lessons and abandoned the Indigenous ways of being and speaking, they were still looked upon as second-class citizens. In its most benign but still damaging form, the idea of educating Indigenous children was conceived as an act of charity, not as their right as people.

Valdiviezo's (2014; Valdiviezo \& Valdiviezo-Arista, 2008) educational research on institutional beliefs and practices has revealed the co-existence of these ideological patterns of exclusion with new discourses that emphasize education not only as a right of Peruvian citizens, including Indigenous people, but also as an obligation of the State. Moreover, rights and obligations are framed on conceptualizations that defy the desire for homogenization as a goal for the welfare of the country (Valdiviezo, 2013b). Framed in global education initiatives that call for access for all to education and for the education of Indigenous people in their own language and with respect to their culture, diversity is defined as a resource and part of the cultural wealth of the nation. The State is called on to fulfill this promise by supporting and providing intercultural and bilingual education to Indigenous Peruvians, but there are also calls, perhaps more tentative, to provide intercultural education to all students.

In a context where ideological patterns of exclusion and diversity discourses co-exist, inclusion in education can be redefined as (1) the sole provision of materials and infrastructure for schools serving Indigenous children, (2) the provision of mainstream (national) learning content, and/or (3) Indigenous children and the community learning in their language, and performing their own cultural practices, along with the learning of Spanish and mainstream content in IBE schools. Thus, the very same public school promoting inclusion as a right of the people and an obligation of the State can enact practices of inclusion in various and sometimes contradictory ways (Valdiviezo \& Valdiviezo-Arista, 2008; Valdiviezo, 2009). We argue that initiatives that aim at changing the conditions of underserved and marginalized sectors need to pay attention to these contradictions and the pervasive forms of exclusion that continue to be a part of Peruvian society and of schools in particular. Otherwise, attempts to solve deep and entrenched societal and economic problems are simply set in motion within a vicious cycle.

\section{Indigenous Language in IBE Teaching and Learning}

The analysis of data from Valdiviezo's ethnographic research with 17 bilingual, SpanishQuechua, teachers in three Indigenous rural IBE schools, points at evidence of teaching practices that resemble any traditional nonIndigenous program (Valdiviezo, 2009, 2013a, 2013c). While expressing alignment with the importance of learning in the mother tongue, Quechua, some IBE teachers 
preferred to teach in Spanish concurrent with traditional societal beliefs of the need for Indigenous children to learn Spanish in order to advance and compete equally with other non-Indigenous children. When speaking about the goals of IBE a teacher referred to the difficulties Quechua-speaking children would face in a Spanish-language-dominant society that does not recognize Quechua, but only Spanish as an asset.

One goal is that students write their language correctly and the other goal is for them to gradually become fluent in Spanish which is going to be their main language of communication beyond school, because Spanish is going to be their main tool to get a job and to perform in a job if they leave their community. [5th Grade IBE Teacher]

These teachers also felt parental pressures to teach the dominant language as it has always been done in school, as opposed to IBE (Valdiviezo \& Valdiviezo-Arista, 2008; Valdiviezo, 2009). In the words of one IBE teacher, 'many parents don't want their children to learn in their native language. They think that if Spanish is their children's only language, no one will surpass them' (Valdiviezo \& Valdiviezo-Arista, 2008, p. 7). Overall, teachers' understandings of bilingual education in IBE emphasized the use of Quechua in the classroom as a source of pride in Indigenous cultural identity (Valdiviezo, 2010, 2013a). This symbolic aim of IBE competed with the urgency and demands of preparing Indigenous children to perform in a non-Indigenous, and mainly intolerant, Spanish-speaking society.

In Valdiviezo's study, the Andean communities where the three schools were located saw the IBE mission of teaching Quechua in school differently. One community opposed their children learning Quechua in school, while the other two celebrated when they witnessed their children reading and writing in Quechua, which drastically differed from their own experiences when they were in school before the creation of IBE. The inclusion of the Indigenous language in IBE was a complex task when observed in the field. As regional varieties of the Quechua language were not represented in the educational materials provided by the Ministry of Education, educators challenged the validity of the materials in the Indigenous language. The IBE teachers involved in Valdiviezo's study were most critical of the content of materials because, even if written in Quechua, they did not reflect the Quechua that the community spoke. IBE teachers discussed at length the importance of offering children the opportunity to see their language reflected in school teaching and learning. They also critiqued topdown initiatives from the government which gave schools materials that were in some cases mere translations of Spanish texts into the Quechua language, and thus not reflective of the children's language and culture.

As has been noted in Valdiviezo's research, most teachers approached parents and the community constantly to gather their support for IBE, both individually but also through meetings and activities. The inclusion of parental presence and contributions in IBE also introduced tensions into the work of teachers. In reaction to experiences of schooling where Indigenous language and culture had been suppressed, parents were concerned that IBE was not going to prepare their children to face mainstream society. They were convinced society would continue to discriminate against Indigenous people. This was a difficult terrain to navigate for teachers and, at times, they were discouraged by parents' opposition to the use of Quechua for instruction. However, it was also gratifying for teachers to witness parents celebrating their children's ability to read and write in Quechua. This nuanced observation of IBE practice revealed grave contradictions within the IBE program. The top-down government efforts to include the Indigenous language and culture in IBE was materialized in exclusionary ways for the local Indigenous communities. At the local level, the use of Quechua in instruction proved to be both a source of tension and a source of pride in the IBE school. 


\section{Quechua Cultures in IBE}

While there were visible shortcomings in the delivery of IBE through government initiatives and resources, teachers were able to engage in assertive efforts that enacted inclusion in language, curriculum, and teaching. As shown in Valdiviezo's research, IBE teachers who were practitioners in the field possessed an in-depth understanding of the need to include local knowledges and cultural practices in IBE. The teachers' understandings were particularly critical, given that government officials who supervised them expressed unawareness and openly opposed the inclusion of Indigenous culture in IBE, thus replicating traditional societal ideologies that excluded Indigenous people from institutions and society. Teachers often questioned top-down pressures and looked for local ways to address cultural diversity in their classrooms. In the words of a 1st grade teacher:

What we need to seek is for all content, all learning to grow from [people's] own Indigenous culture. We ought to seek for curricular areas to be integrated in the values of the region and everything that pertains to their culture. In that vein, not only the language constitutes part of culture. Therefore, we also have to include the life experiences of the community, their world view, their knowledge, their own technology. [1st Grade IBE Teacher in Valdiviezo \& Valdiviezo-Arista, 2008]

IBE teachers sought the inclusion of Indigenous cultural practices through their own exploration of the communities around them. Together with this exploration, IBE teachers deliberately developed a rapport and strong relations with parents and the community. Parents were often found on school grounds taking care of the school infrastructure and preparing meals for the students. They would volunteer to take care of the children and help gather resources for the school. However, parental involvement was also important to IBE when teachers welcomed parents on the school grounds to generate ideas and support for projects that included building a new school library or the organization of the first ever field trip for the whole school, as well as for the performance of Indigenous rituals like giving thanks to mother earth. In all of these instances, teachers were inclusive and welcoming of parents as cultural resources of support to the school.

In both O'Donnell's study of popular education in Argentina and in this study, it is clear that in Indigenous communities, Indigenous parents can have a strong presence in schools. Teachers, in both case studies, were able to build reciprocal relationships with the community and benefitted greatly from these relationships. Parents and community members brought a wealth of resources for IBE teaching and learning in the classroom. Teachers designed curricula based on the economic activities in the community and adapted the school calendar to community activities including celebrations and the harvest season. In Valdiviezo's work it was evident that while the delivery of material help from the parents to the school was ongoing, their ideological contribution presented a challenge for IBE educators. Parents would generously share their cultural practices to be part of the IBE curriculum but were also able to question the inclusion of their native language in the school. This challenge presented the inevitable question: in an education program built on inclusion of Indigenous language and culture, how can inclusion be enacted in such a way as to address parental opposition to teaching and learning in Quechua? Teachers negotiated this ideological challenge in various ways, sometimes successfully and sometimes not. However, they never walked away from parents and the opportunities to meet and talk with them. Contrary to the marginalization of parents from minoritized groups often experienced in non-Indigenous contexts, the presence - material as well as ideological of Indigenous groups in IBE was intrinsic to the values of inclusive education in the program. 


\section{Contributions of IBE to Inclusive Education}

Through their attention to cultural and linguistic practices in their communities, IBE teachers demonstrated cultural sensitivities toward and inclusion of Indigenous language and culture. The inclusion of cultural practices demanded a necessary transformation of the curriculum where Indigenous culture was enacted in the school and the local Indigenous language was utilized in the classroom. Inclusion in IBE was a lived value that teachers were able to enact through parental presence, acceptance and influence in the relations between school and community. These relations were reciprocal, yet they also presented challenges, particularly when some parents would oppose the use of the Indigenous language in school. The navigation of contested terrains was a process teachers often faced directly and never walked away from. They understood that it was impossible to implement IBE without including the Indigenous community, particularly parents.

This inclusion of parents, as beneficial as it was for school infrastructure and material support, carried tensions. Dialogue between the school and the Indigenous community was a necessary part of the process of educating students. IBE teachers used dialogue to address opposition and face conflict productively and as part of a required and ongoing inclusive process. As for the inclusion of Indigenous language, teachers were critical and well aware that the inclusion of Quechua meant inclusion of the local version of the Indigenous language first, together with the cultural meaning that represented local Quechua communities as opposed to translated Spanish texts representative of the mainstream culture.

Similar to what popular educators in Argentina faced, IBE teachers in Peru navigated inclusion by embracing dilemmas and challenges in their own work. Inclusion in the experiences of educators in these programs was enacted in processes that were far from harmonious or uncontested. In everyday experience, IBE teachers embraced inclusion of views opposing IBE and left channels of communication open to parents' voice.

\section{CONCLUSION: CHALLENGING MARGINALIZATION IN MAINSTREAM SCHOOL SETTINGS}

Argentina and Peru are countries with long histories of socioeconomic disparities and exclusion, where only recently education policy and programs have framed inclusion as an important goal. Our ethnographic research of the experiences of inclusive education in programs serving marginalized urban and Indigenous sectors revealed tension and contradiction between the policy of inclusion and its local implementation in education settings that have historically reinforced the exclusion of these sectors. These experiences also showed how educators contested education systems, which in spite of their goal of inclusion were built on exclusionary systems and how these educators developed their own practices of inclusive education. Educators teaching marginalized communities enacted inclusion by creating alternative teaching and learning opportunities for populations who have historically experienced marginalization in the school setting. Inclusion was enacted through criticality, reflection, and creativity, as well as through questioning both existing inequities and political and socioeconomic power structures. Inclusion in these settings questioned the mainstream and its institutions and actively transformed practices.

Teachers created a different education for Indigenous people, as well as poor and working-class communities, through the inclusion of local language and culture. This type of inclusion went beyond symbolic 
practices. Inclusive practices transformed the classroom space, a space that had violently excluded Indigenous people, into a space where culture was enacted and local linguistic practices celebrated. This inclusive education also welcomed processes where criticism was addressed through dialogue as opposed to dogmatically dismissing or denying ideas that ran counter to the status quo. In the creation of a different education for marginalized populations, educators in both studies challenged mainstream teaching and learning, as well as what it meant to be members of an education community. Through localized practices, sensitive to the social, economic and political realities of the populations they served, popular and IBE educators amplified understandings and practices of inclusion.

This chapter shows that the local practices taking place in popular education workshops, as well as in bilingual education programs for Indigenous-language speakers are similar to, and can be applied to, those who primarily identify as classroom teachers in traditional classrooms settings. Documenting responses to neoliberalism and deculturation in education and examining practices to build knowledge from the ground up constitute the field's most important tasks right now, as similar repercussions are ubiquitous in educational spaces worldwide. Practices presented in these cases of inclusive education may inform pedagogy in places where classrooms are isolated from the communities that house them. While popular education and Indigenous programs may seem limited in scope to Latin America, the work of educators presented here may resonate strongly in other communities - with immigrant students in the US and Europe, among others.

\section{REFERENCES}

Ball, S. J., Fischman, G., \& Gvirtz, S. (2003). Toward a neoliberal agenda? Tension and change in Latin America [Introduction].
In S. Ball, G. Fischman, \& S. Gvirtz (Eds.), Crisis and Hope: The Educational Hopscotch of Latin America (pp. 1-18). New York, NY: RoutledgeFalmer.

Darder, A. \& Mirón, L. (2006). Critical pedagogy in a time of uncertainty: A call to action. Cultural Studies $\leftrightarrow$ Critical Methodologies, 6(1), 5-20.

Fink, M. \& Arnove, R.F. (1991). Issues and tensions in popular education in Latin America. International Journal of Educational Development, 11(3), 221-230.

Freire, P. (1985). The Politics of Education: Culture, Power, and Liberation. South Hadley, MA: Bergin \& Garvey.

Jara, O. H. (2010). Popular education and social change in Latin America. Community Development Journal, 45(3), 287-296.

Lewis, P. H. (2002). Guerrillas and Generals: The 'Dirty War' in Argentina. Westport, CN: Praeger.

Macedo, D. P. (2006). Literacies of Power: What Americans Are Not Allowed to Know. Boulder, CO: Perseus Books Group.

Mariátegui, J.C. (1972). Siete Ensayos de Interpretación de la Realidad Peruana. Lima, Perú: Editorial Amauta.

O'Donnell, J. L. (in press). Affecting solidarity: Buenos Aires teachers countering professional alienation and exploitation through yerba mate and new media. In M. Hoffmann \& F. Ramirez (Guest Eds.) [Special issue] The Multicultural Education Magazine: 21st Century Learning and Technology in Diverse Classrooms, Winter.

O’Donnell, J. L. \& Sadlier, S. T. (2017). Performing grief through teacher activism and curriculum: Case studies from Oaxaca and Buenos Aires social movements [Special issue]. The Journal of Inclusive Scholarship and Pedagogy, 26(2), 213-229.

UNESCO. (1990). World Declaration on Education for All. Retrieved from http://unesdoc. unesco.org/images/0012/001275/127583e. pdf

UNESCO. (2000). The Dakar Framework for Action, Education for All: Meeting Our Collective Commitments. Retrieved from http:// unesdoc.unesco.org/images/0012/ 001211/121147e.pdf

UNESCO: International Bureau of Education. (2007). Taller Regional Preparatorio sobre 
Educación Inclusiva: América Latina, Regiones Andina y Cono Sur. Buenos Aires, Argentina. Retrieved from http://www.ibe. unesco.org/fileadmin/user_upload/Inclusive_ Education/Reports/buenosaires_07/argentina_inclusion_07.pdf

United Nations. (2008). United Nations Declaration on the Rights of Indigenous Peoples. Retrieved from https://www.un.org/esa/ socdev/unpfii/documents/DRIPS_en.pdf

Valdiviezo, L. A. (2009). 'Don't you want your child to be better than you?' Enacting ideologies and contesting intercultural policy in Peru. In F. Vavrus \& L. Bartlett (Eds.), Critical Approaches to Comparative Education: Vertical Case Studies from Africa, Europe, the Middle East, and the Americas (pp. 147162). New York: Palgrave Macmillan, Comparative and Development Education series.

Valdiviezo, L.A. (2010). Indigenous Worldviews in Intercultural Education: Teachers' Construction of Interculturalism in a Bilingual Quechua-Spanish Program. Intercultural Education, 21(1), 27-39.

Valdiviezo, L.A. (2013a). Cosmovisiones indígenas y construcciones sobre la interculturalidad en la educación bilingüe [Indigenous cosmovision and constructions about interculturality in bilingual education]. Revista Peruana de Investigación Educativa, 2013(5), 99-123.

Valdiviezo, L. A. (2013b). Vertical and horizontal approaches to ethnography of language policy in Peru. International Journal of the Sociology of Language, 219, 23-46.

Valdiviezo, L. A. (2013c). 'El niño debe aprender en su idioma' [A child must learn in her language]: A teacher's approximations to language policy in an indigenous Peruvian school. In J. Shoba \& F. Chimbutane (Eds.), Bilingual Education and Language Policy in the Global South (pp. 13-29). New York, NY: Routledge, Taylor \& Francis Group.

Valdiviezo, L. A. (2014). Political discourse and school practice in multilingual Peru. In R. Cortina (Ed.), The Education of Indigenous Citizens in Latin America (pp. 187-209). Bristol, UK: Multilingual Matters.

Valdiviezo, L. A., \& Valdiviezo-Arista, L. M. (2008). Política y práctica de la interculturalidad en la educación peruana: análisis y propuesta [Policy and practice of interculturality in Peruvian education]. Revista Iberoamericana de Educación, 45, 1-25. 